\title{
Implementation of rover tank firefighting robot for closed areas based on arduino microcontroller
}

\author{
Ahmed Murad', Oguz Bayat ${ }^{2}$, Hamzah M. Marhoon ${ }^{3}$ \\ ${ }^{1,2}$ School of Engineering and Natural Science, Altinbas University, Istanbul, Turkey \\ ${ }^{3}$ Department of ComputerTechniques Engineering, Al-Esraa University College, Baghdad, Iraq
}

\begin{abstract}
Article Info
\section{Article history:}

Received Apr 1, 2020

Revised Jun 14, 2020

Accepted Aug 26, 2020

\section{Keywords:}

Arduino

Bluetooth HC-05

Fire extinguishing

Mobile robot

Wi-Fi camera

ABSTRACT

Recently, communication via the wireless systems become promising, since the wireless communication system provides several benefits such as the disposal of the wire usage, provides long-distances communication, and the disposal of periodic maintenance of data transmission lines. In robotic science, the wireless system unit is the main part of the mobile robot. Whereas, only wireless communication module responsible for transmitting commands from the transmitter (e.g. mobile or PC) to the receiver (i.e. robot brain) and vice versa. With the increase in population growth and the construction of the urban, fires have become widely spread. It is worth mentioning here that the lives of firefighters are in permanent danger where they may be exposed to the combustion or inhalation of toxic gasses associated with the combustion process. Therefore, become necessary to find effective ways to reduce these risks. In this paper, a rover tank robot is implemented for fire extinguishing in closed areas based on the Arduino microcontroller, flame sensor, and motion sensor. The robot has a small water pump installed on a servo motor to pump water, the first flame sensor placed on the right of the robot's front and the second to the left of the robot's front. When a fire is explored through a flame sensor, the water pump sprays water to the location of the fire. The robot is driven wirelessly utilising the Bluetooth HC-06 module and the Wi-Fi camera utilised for driving purposes. Besides, a passive infrared (PIR) sensor is used to detect the presence of any living organism inside the fire site to alert the robot driver that an organism requires a rescue.
\end{abstract}

This is an open access article under the CC BY-SA license.

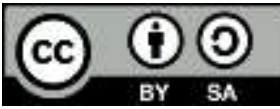

\section{Corresponding Author:}

Hamzah M. Marhoon

Department of Computer Techniques Engineering

Al-Esraa University College

Baghdad, Iraq

Email: hamzaalazawy33@yahoo.com

\section{INTRODUCTION}

Since many years, fires have continued and the lives of the firefighters are constantly facing its risks, almost daily, such as exposure to deformities, combustion or inhalation of the toxic gases. Fire accidents in industries involve working with inflammable materials, such as petroleum or other chemicals liquids. When firefighting units are intervening in such situations, there is a high chance of losing the life of firefighters. In everyday life, it is not possible to always rely on human patrol to detect and extinguish the fire at the scene of the working area $[1,2]$.

If an automated system is used to monitor the proximity of fire accidents, we can quickly have an immediate indication to detect the fire. This will be extremely effective in factories, suburban areas, and other institutions where the potential for fire is high. In order to maintain safety for the workers in this field, mobile robots and wireless communication could be utilised to carry out this task. The automatic robot is designed to prevent the further spread of the fire that could lead to possible human losses or damage to property so that the fire extinguishing robot will help firefighters do their job safely [3]. The robot is an electromechanical device 
used in science or industry to replace human labour or to perform the functions assigned to it. A robot may interact with its environment; sometimes it may resemble a human being physically, or it may perform its duties as a human being. The robot component can be summarised as follows: brain, body or robot structure, actuators, sensors, and power source. Robot brain can be defined as a module which prepares sensory input in the specific situation of the body and that directs the device to take the required action [4].

There are a lot of controllers and microcomputers can be utilised as a robot brain, some of these are the Arduino microcontroller, peripheral interface controller (PIC), and raspberry Pi microcomputer. The choice of the appropriate unit of these microcontrollers depends on a number of factors, including the speed of processing of the data, the design cost and the number of sensors connected to the robot, since each microcontroller offers different specification over the other. After selecting the appropriate brain for the robot, the method by which the robot will be driven should be determined. There are some popular methods for a robot navigating such as wall-follower, edge detection, line follower, and controlled wirelessly [5-9].

A rover tank robot will be designed and implemented in this work to extinguish fires, particularly in closed areas to maintain the safety for the firefighters. This type of robot structure was chosen to ensure the smooth driving and overcome to the presence of the obstructions at the site of the fire. The Arduino Uno microcontroller has been utilised as a robot brain for ease of programming as well as for the cheap of the manufacturing costs. In order to maximize the benefits of the designed robot, remote control technology has been used by the Bluetooth HC-06 system, which operates on the frequency range from 2.402 to $2.480 \mathrm{GHz}$, and the driving process is carried out via the Android smart mobile phone via an application installed inside the smartphone. The organisation of the paper can be summarised as follows: Section 2 provides a brief description of the hardware that is used in the design of the proposed robot. Section 3 presents the necessary steps of the robot manufacturing process and the working principle of the proposed robot. Also, comprises a presentation for the obtained results after applying the practical test to the proposed robot. Finally, Section 4 illustrates the concludes of this paper.

\section{SYSTEM HARDWARE}

This subsection of the paper includes a brief description of the Arduino microcontroller as well as the electronic sensors and the other equipment that will be utilised in the construction of the proposed robot.

\subsection{Arduino uno microcontroller}

The Arduino is a microcontroller board with an integrated software suite for programming to be as an embedded system board. The hardware consists of simple and open-source component design for the Arduino board with an AVR processor as well as a boot loader that runs on the AVR to support the input/ output (I/O) ports [10].

The software is an open-source called the integrated development environment (IDE) built on the standard of the $\mathrm{C} / \mathrm{C}++$ programming language. In other words, an Arduino is a tiny computer able to reprogramming to prepare the I/O between the device and peripheral components. There are many types of the Arduino microcontroller boards, and the most popular type is the Arduino uno board which is based on the Microchip ATmega328P [11].

This type includes a 14-digital pin can be utilised as digital I/O, 6 pins of them can be utilised to provide an analogue output through the pulse width modulation technique; while contains 6-analogue input pins utilised to read the data of the different types of sensors such as temperature sensor, gas sensor, and soil humidity sensor. Also, the Arduino Uno board have a $16 \mathrm{MHz}$ crystal oscillator, a USB connection, a power jack, ICSP header, and a reset push-button [12,13]. Figure 1 illustrates the Arduino Uno microcontroller board



Figure 1. Arduino uno microcontroller 


\subsection{Flame sensor module}

This type of sensors is designed to detect and respond to the presence of the flame. The flame sensor is utilised to detect the fire source in the range up to $100 \mathrm{~cm}$. Also, it is able to detect the ordinary light sources which have a wavelength between $760 \mathrm{~nm}$ and $1100 \mathrm{~nm}$. To ensure the best detection performance, the sensor installation area should be empty from the light sources in the discussed range. Figures 2 and 3 ; respectively, illustrate the flame sensor module and the plot of the sensor analogue output voltage vs the detection range [14-16].

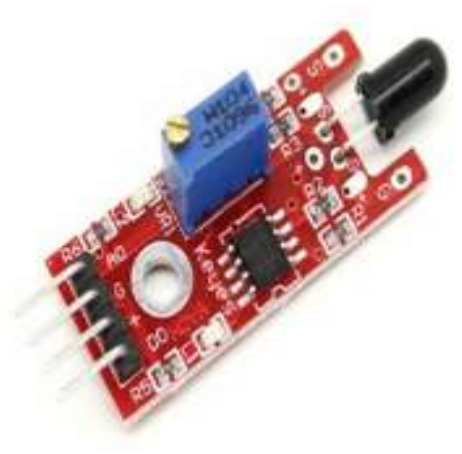

Figure 2. Flame sensor module

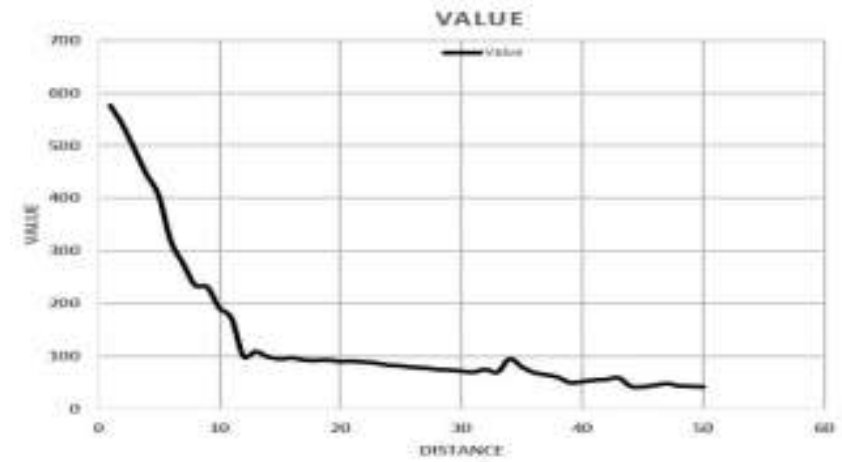

Figure 3. Flame sensor output voltage vs distance

\subsection{Bluetooth module}

The HC-06 Bluetooth module is a slave Bluetooth module created for the wireless serial communication, the slave module signifies that the module is able to receive the serial data during serial data is sent out from a master device such the smartphones or PC. Many programmed apps on the smart mobile phone can be utilised to send the commands to the module which in turns transferred to the Arduino or the other available microcontroller. The Arduino and actuators, in turn, respond accordingly to the received commands and doing the required task, as specified in the source code that uploaded to the Arduino, Figure 4 illustrates the HC-06 bluetooth module [17-20].

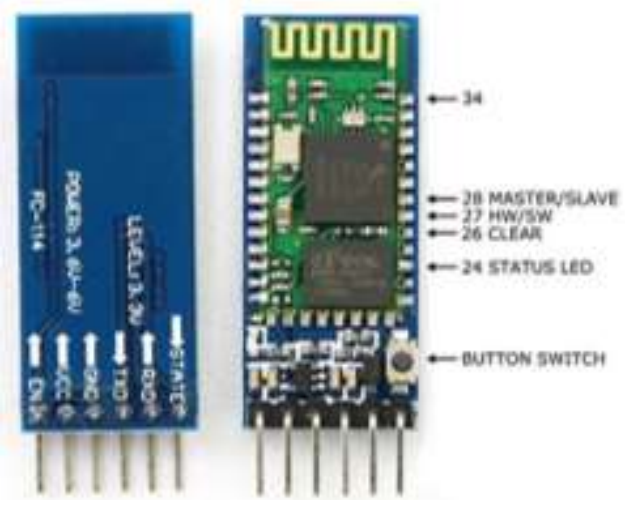

Figure 4. HC-06 bluetooth module

\subsection{Rover tank robot structure}

This type of robot structures is characterised by high stability and the ability to overcome obstacles, especially difficult places due to the presence of the conveyor belt in the robot tires, which increases its ability to overcome fossils and ascending the heights, which makes it very suitable for the performance of tasks and functions in the harsh environment. A rover tank robot was used as a planetary surface exploration device designed to move across the solid surface on a planet or other planetary-mass celestial bodies [20-23]. From the mentioned characteristics of this structure, it will make it very effective to work in the field of firefighting as a mobile robot, Figure 5 illustrates the rover tank robot structure. 


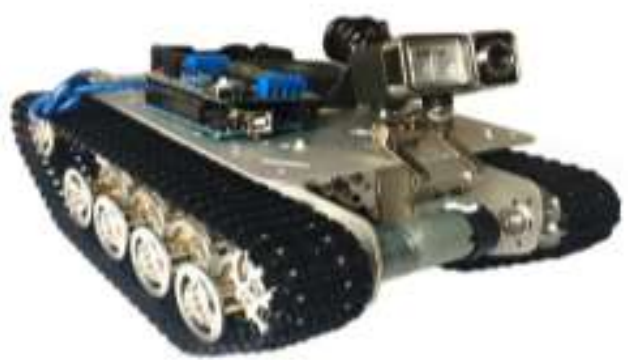

Figure 5. Rover tank robot structure

\subsection{Servo motor}

Servo motors are basically a one form of the DC motors with position feedback to improve its performance. This signifies that the microcontroller is able through programming to make the servo move to the desired position by changing the pulse time (i.e. pulse length), as shown in Figure 6 . The standard servo motors can be moved from 0 to $180^{\circ}$ and another type is moved from 0 to $360^{\circ}$. The servo motor is distinguished from the regular DC motor by its strong torque, high performance, and ease of operation as well as it doesn't require an additional driving circuit $[24,25]$. Also, it is characterized by a constant speed, with the load changes. Servo motor comprises three terminals, two of which are for power feeding, and the left terminal is for control, which is directly coupled to the Arduino microcontroller [26], as illustrated in Figure 7.

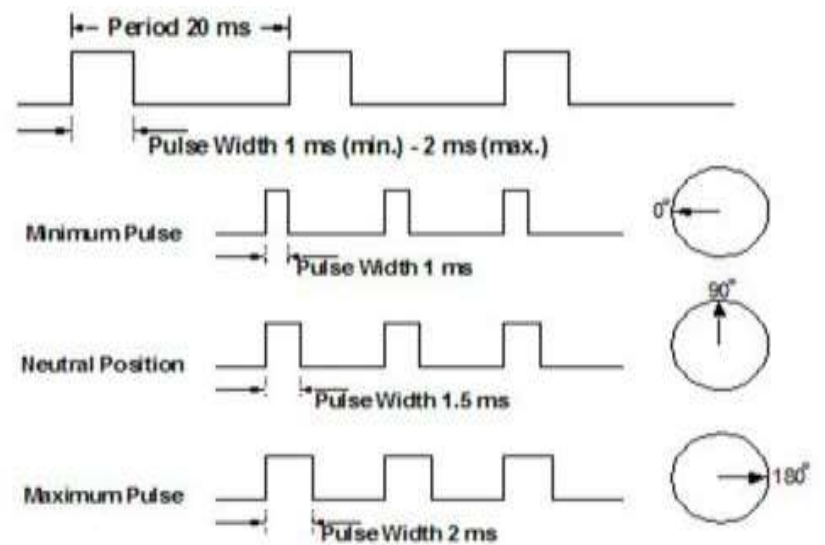

Figure 6. Servo motor position corresponding to the length of the pulse

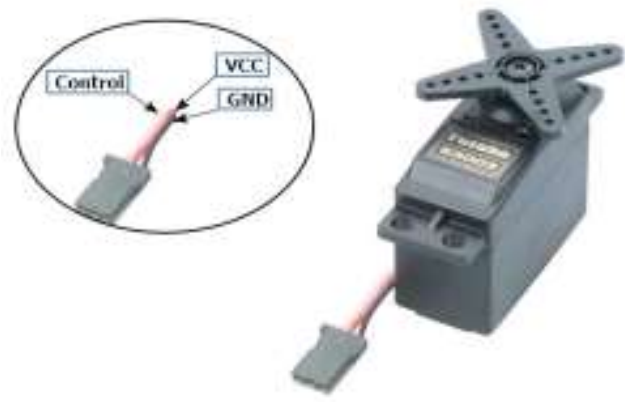

Figure 7. Servo motor module

\section{PROPOSED ROBOT DESIGN AND IMPLEMENTATION}

In this subsection, the steps for implementing and working principle of the proposed robot for firefighting will be explained, as well as this subsection includes a presentation of the results obtained after the conducting a practical test of the robot.

\subsection{Robot implementation}

In this work, the "DD-1 chassis kits caterpillar crawler" tank robot structure was used to build the proposed fire extinguishing robot based on the Arduino Uno microcontroller. This type of structures contains an L9110 built-in motor driver circuit, which facilitates the hardware connection and the design process. In this work, a flame sensor module has been installed in the right front of the robot and another in the left front of the robot. A PIR sensor is utilised also for the purpose of detecting the presence of any living organism inside the fire zone. Further, a small water pump also has been installed on the servo motor and controlled by utilising a transistor as a switch, where the pump is fed externally from a source of $7.2 \mathrm{~V}$ and the Arduino microcontroller is limited to giving a pulse of voltages to the base of the transistor to turn the water pump ON or OFF, as shown in the connection diagram of Figure 8. A Wi-Fi camera with voice and video situated at the 
front of the robot was utilised to facilitate the driven process. The robot is fully wireless driven by Bluetooth technology utilising an Android-compatible app that is shown in Figure 9. The numbers shown in Figure 9 indicates the function of each button that appears on the graphical user interface for the Android app and which are summarised in Table 1. Each button contains a specific character that it sends to the Arduino when it is pressed, therefore the Arduino performs the required function. For example, when the move forward button is clicked, the app will send an ' $F$ ' character to the Arduino so that the Arduino instruct the robot motors to move forward, and so on with the rest of the buttons, the other buttons characters' of the Android app are shown in Table 2.

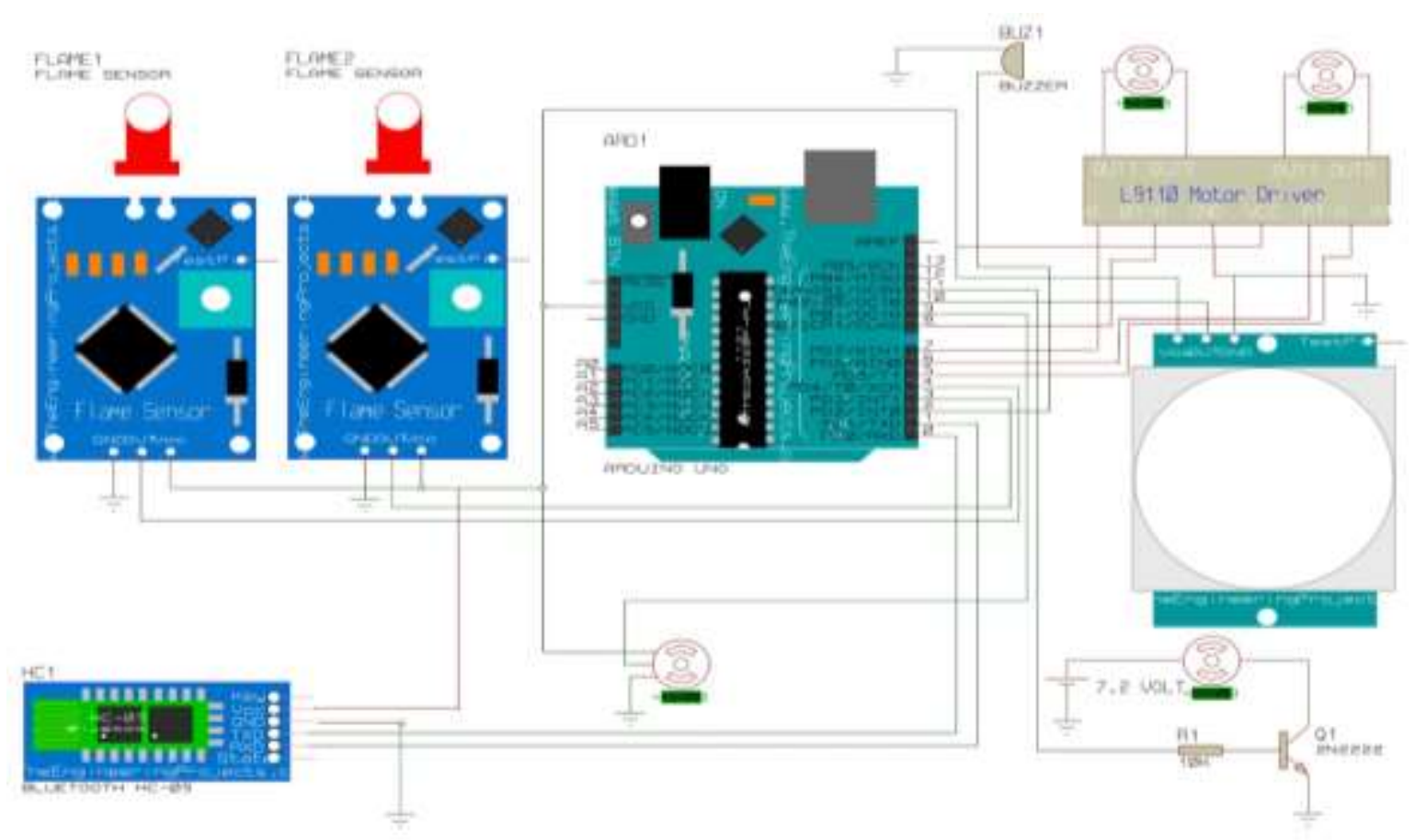

Figure 8. Connection diagram of the proposed robot

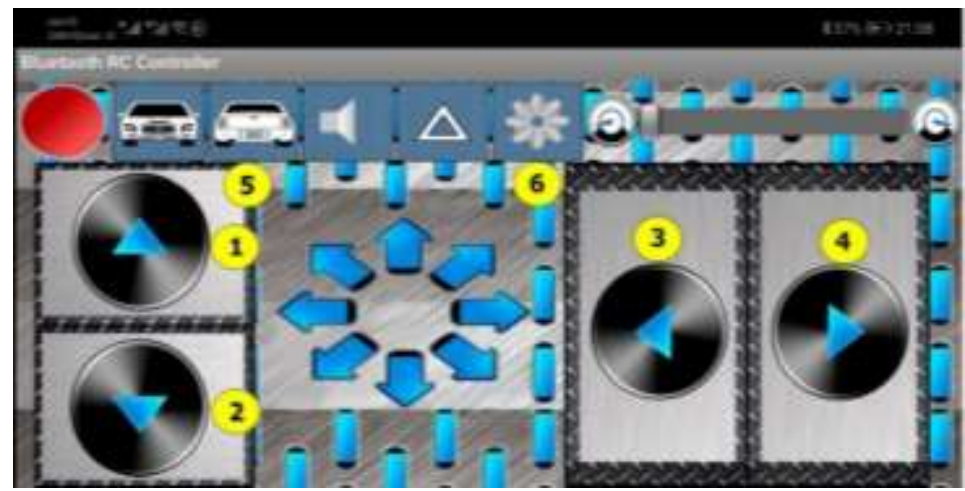

Figure 9. The graphical user interface of the android app

Table 1. The function of each button in the android app

\begin{tabular}{cc}
\hline Number & Description \\
\hline 1 & Move Forward \\
2 & Move Backward \\
3 & Move Left \\
4 & Move Right \\
5 & Turn ON the Water Pump \\
6 & Connect with Arduino Bluetooth
\end{tabular}

Table 2. Characters of the android app

\begin{tabular}{cc}
\hline Character & Function \\
\hline ' $F$ ' $\mathrm{B}$ ' & Forward Direction \\
' $\mathrm{R}$ ' & Backward Direction \\
' $\mathrm{L}$ ' & Right Direction \\
' $\mathrm{u}$ ' & Left Direction \\
\hline
\end{tabular}


After completing the components assembly for the proposed firefighting robot, the first step is to start the operation of the robot by means of a power switch, after which the wireless connection between the Android app as well as the Arduino HC-06 Bluetooth should be established to send the operation commands of the forward, backward, right, and left direction. When the robot enters the fire site and in the case of one of the flame sensors detect the fire, the water pump starts spraying the water to right/left until the fire is extinguished. Sometimes the sensor can be subjected to sudden damage or the presence of a few amount of fire and its presence can't be distinguished, so the water pump can be operated manually through the Android app with the help of the Wi-Fi camera. In the case that there is any living organism in the vicinity of the place of fire, its presence will be detected by the PIR sensor, and which will alert the robot brain (i.e. Arduino UNO) to tell the robot driver through the buzzer there is a living organism needs to the rescue. Figures 10 and 11; respectively, illustrates the block diagram of the proposed robot and the implemented model for the proposed robot.

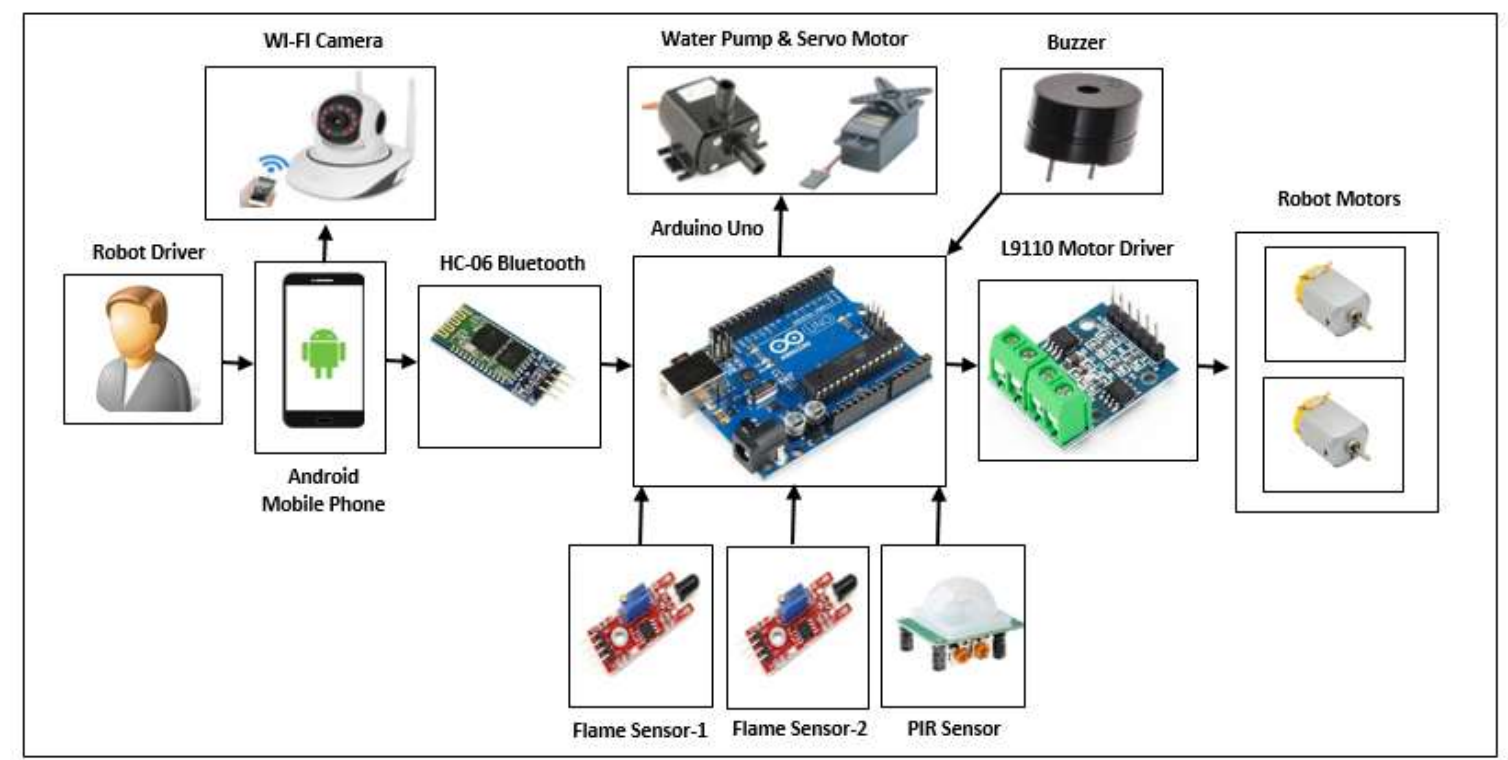

Figures 10. Block diagram of the implemented robot

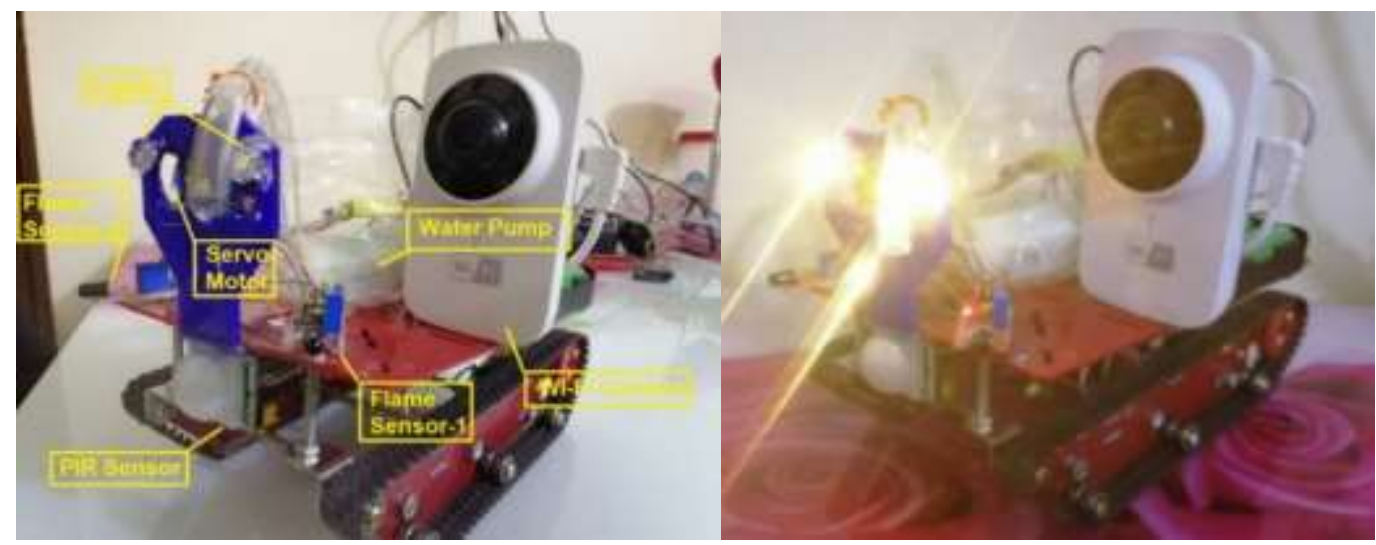

Figure 11. The implemented firefighting robot

\subsection{Results and discussion}

After the completion of the robot operation and the establishment of a wireless connection between the robot and the android app, a practical test was carried out. The practical test begins by turning the Wi-Fi camera ON and driving the robot towards the fire area, where the fire candles are placed in front of the robot, as shown in Figure 12. 
In the first step of the practical test, the water tank was raised from the robot to ensure that the water pump was functioning properly in the case of fire detection, as indicated in Figure 12. The next step is to place the water tank on the robot and direct the robot to the location of the fire (i.e. fire candles), after that the robot moves the servo motor and directs the water left and right over the fire candles to be extinguished, as illustrated in Figure 13.

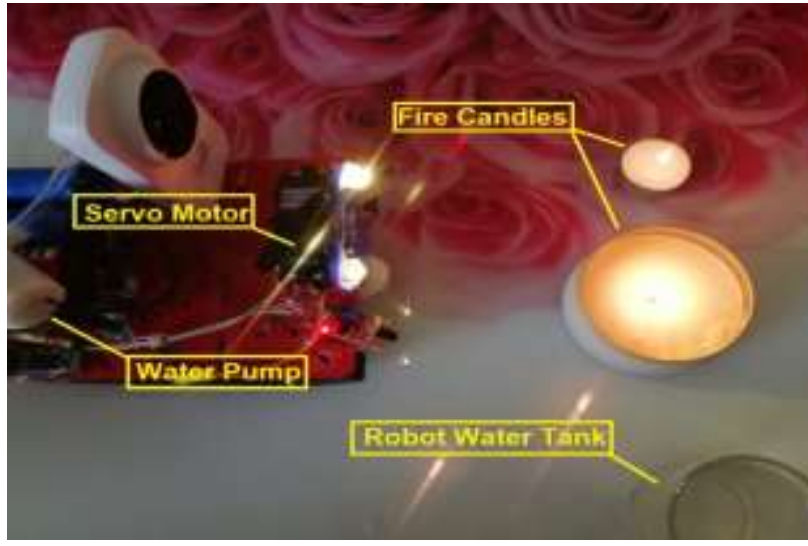

(a) Implemented robot without water tank
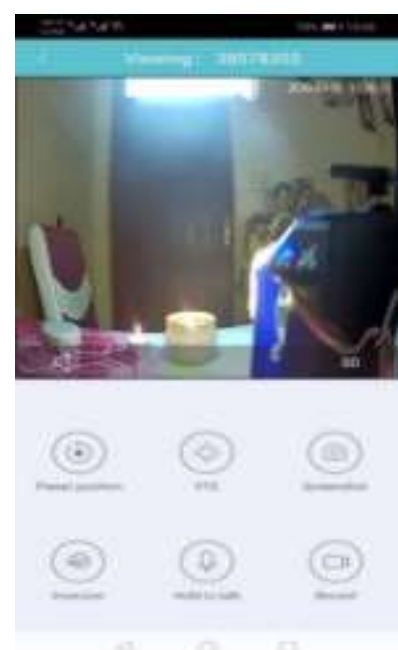

(b) Robot monitoring via the Wi-Fi camera

Figure 12. Steps of the practical test for the implemented robot

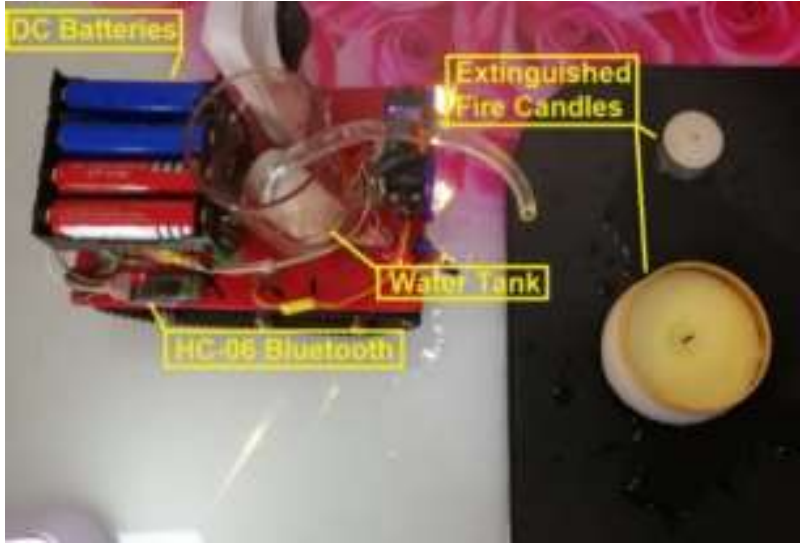

(a) Implemented robot with water tank
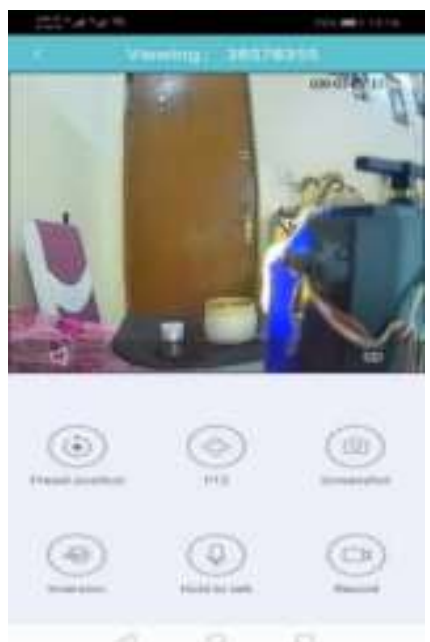

(b) Robot monitoring via the Wi-Fi camera

Figure 13. The extinguished fire candles by the robot

\section{CONCLUSION}

A novel of the rover tank firefighting robot is presented in this paper. A simple and low-cost firefighting robot based on the Arduino Uno microcontroller was implemented and tested in this work. The main contribution of this work is to develop a rover tank firefighting robot especially utilised in the extinguishing of the indoor fires that are difficult to reach easily. Two flame sensors and the PIR sensor were utilised to detect the presence of the fire and the motion of living organisms respectively, while a Wi-Fi camera was utilised to facilitate the robot's driving process. Furthermore, the servo motor was utilised to directs the spread of the waters toward the direction of the fire. Finally, the robot was operated as well as tested practically, good efficiency and performance were achieved. 


\section{REFERENCES}

[1] A. Çakir, N. Farooq, and E. Ezzulddin, "Fire-Extinguishing Robot Design by Using Arduino," IOSR J. Comput. Eng., vol. 18, no. 6, pp. 113-119, 2016.

[2] N. MS, D. T V, S. Michahial, and M. Shivakumar, "Fire Extinguishing Robot," Int. J. Adv. Res. Comput. Commun. Eng., vol. 5, no. 12, pp. 200-202, 2016.

[3] C. Paper and S. Mohammed, "Development and Implementation of Arduino Microcontroller Based Dual Mode Fire Extinguishing Robot," in 2017 IEEE International Conference on Intelligent Techniques in Control, Optimization and Signal Processing (INCOS), Srivilliputhur, pp. 1-4, 2017.

[4] I. A. Taha and H. M. Marhoon, "Implementation of Controlled Robot for Fire Detection and Extinguish to Closed Areas Based on Arduino," TELKOMNIKA Telecommunication, Computing, Electronics and Control, vol. 16, no. 2 , pp. 654-664, 2018.

[5] H. Nizam, M. Shah, M. F. Abdollah, Z. Kamis, M. Shahrieel, and M. Aras, "Develop and implementation of PC based controller for humanoid robot using digital potentiometer," Indonesian Journal of Electrical Engineering and Computer Science (IJEECS), vol. 15, no. 1, pp. 104-112, 2019.

[6] A. Çakir and A. B. Badri, "Fire Tracking and Suppression Mobile Robot - Design and Construction," Indonesian Journal of Electrical Engineering and Computer Science (IJEECS), vol. 5, no. 1, pp. 159-165, 2017.

[7] M. Rivai, D. Hutabarat, Z. Muhammad, and J. Nafis, "2D mapping using omni-directional mobile robot equipped with LiDAR," TELKOMNIKA Telecommunication, Computing, Electronics and Control, vol. 18, no. 3, pp. 1467$1474,2020$.

[8] A. Maity, A. Paul, P. Goswami, and A. Bhattacharya, "Android Application Based Bluetooth Controlled Robotic Car,” Int. J. Intell. Inf. Syst., vol. 6, no. 5, pp. 62-66, 2017.

[9] W. Hidayat, S. Anuar, N. B. Azhar, Z. Manap, Y. Soon, and M. M. Ibrahim, "Line Follower Mobile Robot for Surveillance Camera Monitoring System,” Journal Telecommun. Electron. Comput. Eng., vol. 10, no. 2, pp. 1-5, 2018.

[10] H. M. Marhoon and I. A. Taha, "Design And Implementation Of Intelligent Circuit Breaker For Electrical Current Sensing And Monitoring”, International Journal Of Core Engineering \& Management," Int. J. Core Eng. Manag., vol. 4, no. 11, pp. 39-49, 2018.

[11] A. Najihah, M. H. Habaebi, and F. A. Rahman, "Design and Implementation of Visible Light Communication based toys," Bull. Electr. Eng. Informatics, vol. 8, no. 3, pp. 960-969, 2019.

[12] S. M. Ahmed and H. M. Marhoon, "Implementation of smart anti - theft car security system based on GSM," Int. J. Eng. Technol., vol. 7, no. 4, pp. 5261-5265, 2019.

[13] O. K. Mohammed, O. Bayat, and H. M. Marhoon, "Design and implementation of integrated security and safety system based on internet of things," Int. J. Eng. Technol., vol. 7, no. 4, pp. 5705-5711, 2019.

[14] H. M. Marhoon, M. I. Mahdi, E. D. Hussein, and A. R. Ibrahim, "Designing and Implementing Applications of Smart Home Appliances," Mod. Appl. Sci., vol. 12, no. 12, pp. 8-17, 2018.

[15] B. Sarwar, I. Bajwa, N. Jamil, S. Ramzan, and N. Sarwar, "An Intelligent Fire Warning Application Using IoT and an Adaptive Neuro-Fuzzy Inference System," Sensors (Basel)., vol. 19, no. 14, pp. 1-18, 2019.

[16] S. Wadhwani, U. Singh, P. Singh, and S. Dwivedi, "Smart Home Automation and Security System using Arduino and IOT," Int. Res. J. Eng. Technol., vol. 5, no. 2, pp. 1357-1359, 2018.

[17] A. Wibowo, "Communication Concept Between Bluetooth As a Master and Slave To Exchange Digital Information," Int. J. Eng. Adv. Technol., vol. 9, no. 2, pp. 5468-5470, 2019.

[18] C. S. Tyagi, M. Agarwal, and R. Gola, "Home Automation Using Voice Recognition And Arduino," Int. J. Recent Trends Eng. Res., vol. 2, no. 7, pp. 1-6, 2016.

[19] M. Asadullah, I. S. Member, K. Ullah, and I. Member, "Smart Home Automation System Using Bluetooth Technology," in 2017 International Conference on Innovations in Electrical Engineering and Computational Technologies (ICIEECT), IEEE, pp. 1-6, 2017.

[20] R. K. Singh, A. Sarkar, D. Chakravarty, P. Goyal, V. Lodhi, and A. Sharma, "Bluetooth communication controlled robot based on gesture recognition," in 2015 IEEE International Transportation Electrification Conference (ITEC), pp. 1-5, 2015.

[21] B. Wilcox and K. Yoshida, "Space Robots and Systems. Springer," Berlin, Heidelberg, pp. 1031-1063, 2008.

[22] M. David and J.-D. Yoder, "Introducing Mechanical Engineers to Microprocessors With Arduino Tank Robots," in 122nd ASE Annual Conference\& Exposition, American Society for Engineering Education, pp. 2610251$26102511,2015$.

[23] K. Kosasih, E. M. Sartika, and M. J. Hasugian, “The Intelligent Fire Fighting Tank Robot,” Electr. Eng. J., vol. 1, no. 1 , pp. 73-80, 2010.

[24] A. S. Sadun, J. Jalani, and J. A. Sukor, "A Comparative Study on the Position Control Method of DC Servo Motor with Position Feedback by using Arduino," in Proceedings of Engineering Technology International Conference (ETIC 2015), no. August 10-11, pp. 1-6, 2016.

[25] E. I. Agustin, R. T. Yunardi, and A. A. Firdaus, "Voice recognition system for controlling electrical appliances in smart hospital room," TELKOMNIKA Telecommunication, Computing, Electronics and Control, vol. 17, no. 2, pp. 965-972, 2019.

[26] A. Bhargava and A. Kumar, "Arduino controlled robotic arm," in International Conference on Electronics, Communication and Aerospace Technology ICECA, IEEE, 2017, pp. 376-380. 